\title{
George Sand Critique 1833-1876, Textes de George Sand sur la littérature, présentés, édités et annotés et George Sand Littérature et Politique
}

Sous la direction de Christine Planté, Tussan, Éditions du Lerot, 2006, 804 pages et sous la direction de Martine Reid et Michèle Riot-Sarcey, Nantes, Éditions Pleins Feux, 2007, Collection Horizons Littéraires, 253 pages

\section{Máire Cross}

\section{(2) OpenEdition}

\section{Édition électronique}

URL : https://journals.openedition.org/clio/9969

DOI : $10.4000 /$ clio.9969

ISSN : 1777-5299

Éditeur

Belin

Édition imprimée

Date de publication : 31 décembre 2010

ISBN : 978-2-8107-0098-1

ISSN : $1252-7017$

Référence électronique

Máire Cross, « George Sand Critique 1833-1876, Textes de George Sand sur la littérature, présentés, édités et annotés et George Sand Littérature et Politique », Clio. Femmes, Genre, Histoire [En ligne], 32 | 2010, mis en ligne le 31 décembre 2010, consulté le 28 avril 2022. URL : http://

journals.openedition.org/clio/9969; DOI : https://doi.org/10.4000/clio.9969

Ce document a été généré automatiquement le 28 avril 2022.

Tous droits réservés 


\section{George Sand Critique 1833-1876, Textes de George Sand sur la littérature, présentés, édités et annotés et George Sand Littérature et Politique}

Sous la direction de Christine Planté, Tussan, Éditions du Lerot, 2006, 804 pages et sous la direction de Martine Reid et Michèle Riot-Sarcey, Nantes, Éditions Pleins Feux, 2007, Collection Horizons Littéraires, 253 pages

Máire Cross

1 La richesse des œuvres de George Sand ne cessent de nous éblouir: deux ouvrages témoignent de l'étendue de sa production littéraire dans un contexte historique bien précis grâce à des chercheurs connus et moins connus qui ont soigneusement édité ses écrits. Le contexte est d'autant plus important pour notre compréhension de son engagement public. Contrairement à la notion de l'auteur romantique qui se coupe du monde dans une solitude artistique, George Sand est ici dans sa splendeur de femme engagée, qui communique avec d'autres artistes souvent d'une manière politique, dans son sens le plus large. C'est une ironie que cet aspect de sa face publique et sérieuse ait été si peu apprécié avant le développement des études féministes.

Les essais réunis dans ces deux ouvrages forment un bel ensemble de critiques de celle qui n'est pas toujours reconnue comme une des plus grandes figures de la critique littéraire $\mathrm{du} \mathrm{XIX}^{\mathrm{e}}$ siècle. Ils démontrent à quel point Sand aimait lire et écrire, et absorber le travail de ses contemporains, célèbres ou inconnus. Le but du premier recueil est de faire redécouvrir la production critique de George Sand en rassemblant des essais dispersés dans d'autres publications de ses œuvres. Les textes de Sand sont bien présentés par les chercheurs qui avaient déjà réfléchi collectivement dans une équipe de recherche et qui donnent des informations utiles aux non-spécialistes. Sand avait une excellente connaissance de la production littéraire du passé des hommes et des femmes de la France et de l'étranger (voir sa lecture de Shakespeare ou de 
Rousseau). Elle publia des commentaires sur une grande variété de styles et de textes de géants de la littérature tels que Victor Hugo, d'hommes et de femmes politiques, Louis Blanc et l'américaine Harriet Beecher-Stowe. Plus intéressante encore, l'occasion qu'offre ce livre d'avoir un aperçu de l'opinion de Sand sur la production littéraire de ceux qu'elle soutenait et pour qui l'écriture était une lutte sociale et littéraire, l'ouvrier poète Charles Poncy entre autres. Les chercheurs font sortir de l'oubli non seulement ce côté négligé de Sand mais aussi plusieurs pièces obscures, leurs auteurs et les moments de passion politique du xIX ${ }^{e}$ siècle dont Sand fut actrice et témoin.

Le deuxième recueil permet d'interpréter d'une façon très détaillée le rôle important que joua George Sand dans la vie politique, surtout après le moment bien connu où elle soutint le gouvernement provisoire de 1848 mais refusa d'intervenir directement en faveur des droits des femmes, ce qui ne l'a pas empêchée d'agir pour leur émancipation et d'adopter une position radicale en d'autres occasions moins étudiées. Certes elle apprécia sa vie artistique et saisit toute occasion de s'exprimer en littérature, mais ce sont nous les lecteurs de ses critiques qui bénéficions de sa générosité professionnelle. Le livre nous rappelle que Sand connut au cours de sa longue vie plusieurs régimes politiques. Les chapitres débattent de plusieurs aspects des liens entre la vie littéraire et les évolutions sociales de son époque. Les contrastes sont multiples : citadine de Paris et grande Dame de Nohant, républicaine d'esprit, socialiste romantique, romancière à grand succès sous le Second Empire et protagoniste du roman et de la culture pour les masses, elle représente à elle seule les grands phénomènes de la littérature française. Ces deux recueils de recherches approfondies nous informent donc mieux sur la complexité du rapport entre lecteurs et écrivains, sur leur contribution à la construction de leur espace social, ainsi que sur les facteurs sociaux politiques qui ont joué sur eux. 